\title{
Effect of botulinum toxin in selected chronic anal fissure patients: long-term results
}

\author{
Zülfikar Karabulut, Pașa Doğan, Gökhan Moray \\ Department of General Surgery, Baskent University Faculty of Medicine, Ankara, Turkey
}

Prz Gastroenterol 2012; 7 (6): 383-385

DOI: $10.5114 / p g .2012 .33048$

Key words: anal fissure, surgical, treatment.

\begin{abstract}
Address for correspondence: Zülfikar Karabulut Ass. Prof., Department of General Surgery, Baskent University Faculty of Medicine, Sahil yolu Grand Usta VIP apt. kat: 5, No: 13, 07400 Alanya, Turkey, phone: +90 5325044823 , fax: +90 2425112350 , e-mail: drkarabulut33@yahoo.com
\end{abstract}

\begin{abstract}
Aim: To evaluate the effect of botulinum toxin injection and determine the long-term results in chronic anal fissure patients. Material and methods: Twenty patients with chronic anal fissure were treated by botulinum toxin between September 2005 and December 2006. All patients were fully informed about botulinum toxin treatment and received 25 units of botulinum toxin. After botulinum injections all patients were physically examined every week for 2 months. The follow-up period for long-term recurrences was approximately 48 months. All patients were evaluated for bleeding, pain, infection, incontinence and healing of the fissure by two surgeons. If chronic anal fissure showed no healing within 4 weeks, patients received re-injection therapy of botulinum toxin. Two patients received re-injection and 2 patients who did not want to receive re-injection were treated with lateral internal sphincterotomy (LIS).

Results: Eighteen patients completely healed; 2 of these received a second injection, and 2 others underwent surgery. Flu-like symptoms occurred as a side effect in 1 patient after botulinum injection. At the end of the study the healing rate was $90 \%$. In this study complications such as incontinence, infection, or recurrence were not observed.

Conclusions: In selected patients whose symptoms persisted less than 1 year, botulinum toxin can be recommended as an alternative therapy for chronic anal fissure, because of its high healing rates and ease of the procedure.
\end{abstract}

\section{Introduction}

Anal fissure is a benign pathology which is characterized by a longitudinal tear in the distal anal mucosa [1]. It is also known as one of the most common painful anal diseases in proctology. On examination, the anal fissure is seen as a split that extends from the anal verge to the dentate line. Proximal hypertrophic anal papilla and a characteristic skin tag frequently accompany the ulcer in chronic forms. It generally involves the internal anal sphincter and causes rectal pain and bleeding during and after defecation [2]. It is usually seen in the posterior midline but approximately $10 \%$ of fissures in women and $1 \%$ in men occur in the anterior midline $[2,3]$. Multiple anal fissures and lateral fissures can also be seen with Crohn's disease, ulcerative colitis, tuberculosis, human immunodeficiency virus (HIV), and syphilis [2].

The pathogenesis of chronic anal fissure (CAF) has not been clearly explained. Anal trauma is claimed as an initiating factor. Increased rectal pressure can cause a tear during defecation, especially in the posterior midline, because the posterior midline is a relatively less perfused part, then the other sections of the anal canal. Spasm of the internal anal sphincter and poor blood supply in the posterior midline increase local ischemia and prevent healing of the anal fissure [3].

Lateral internal sphincterotomy has been widely performed as a gold standard treatment for chronic anal fissures with a success rate of $94-100 \%[4,5]$. Despite high success rates of surgical treatment, new approaches such as less invasive methods have been sought due to surgical morbidity, loss of work days and hospitalization costs.

\section{Material and methods}

From September 2005 to December 2006, 20 selected patients with chronic anal fissure were evaluated. 
The diagnosis of CAF was based on the following criteria: evidence of a posterior circumscribed ulcer with a skin tag, induration at the edges and exposure of the horizontal fibers of the internal anal sphincter, and persistent symptoms (post-defecatory severe pain and bleeding) for more than 2 months. All patients were informed about the effects, side effects, healing rates and complications of botulinum toxin $\mathrm{A}$ as a routine procedure.

Patients who had anal fistula, abscess, symptomatic hemorrhoids, acute fissure ( $<6$ weeks), coexistence of inflammatory bowel disease, symptoms that persisted for more than 12 months and those who had previously undergone anal surgery were excluded from the study. All patients were treated by two surgeons and they underwent a pretreatment evaluation by clinical assessment and anoscopy.

The $100 \mathrm{U}$ vials of lyophilized botulinum toxin $\mathrm{A}$ (BOTOX, Allergan Pharmaceuticals, Ireland) were stored at a temperature of $-20^{\circ} \mathrm{C}$ and diluted in saline to $1 \mathrm{ml} /$ $25 \mathrm{U}$ on the day of treatment. With an insulin syringe $12.5 \mathrm{U}$ of botulinum toxin A was injected into both sides of the fissure and $12.5 \mathrm{U}$ of botulinum toxin A was injected into the internal anal sphincter at the 9 o'clock level according to clockwise under digital examination in the prone jackknife position. No sedation or anesthesia was used for this procedure. All patients were given an analgesic after the intervention and discharged on the day following the intervention. All patients were advised to eat a high-fiber diet and given a prescription for laxatives.

\section{Results}

Twenty patients with CAF were treated by botulinum toxin A between September 2005 and December 2006 at our center. Fourteen patients were female (70\%), 6 patients were male (30\%) and median age was 40.6 (range: 23-55) years. Fourteen fissures were posterior (70\%), 4 were anterior (20\%) and 2 patients had multiple (anterior and posterior) fissures. Median duration of symptoms was 6.3 months ( 2 to 12 months). The char-

Table I. Characteristics of 20 patients with chronic anal fissure

\begin{tabular}{lc} 
Characteristic & No. of patients \\
\hline Mean age [years] & 40.6 \\
\hline Sex (men/women) & $6 / 14$ \\
\hline Duration of symptoms [months] & 6.3 \\
\hline Site of fissure (posterior/anterior/both) & $14 / 4 / 2$ \\
\hline Bleeding & 18 \\
\hline Pain & 20
\end{tabular}

acteristics of patients are shown in Table I. All patients were followed up for healing of the fissure, possible side effects and complications every 2 weeks during 2 months. If chronic anal fissure showed no healing within 4 weeks after botulinum injection, a second injection was planned. Two patients received re-injection and 2 patients refused a second injection due to continuing extreme pain. So they were treated by lateral internal sphincterotomy. Flu-like syndrome was seen in $1 \mathrm{pa}$ tient after botulinum toxin injection. Four patients who presented with short-term failure after botulinum injection completely healed with repeated injection and LIS. After 2 months they were reexamined at 6-month intervals for recurrence during 1 year. All patients were contacted and questioned by telephone each year during 48-month follow-up for their satisfaction and possible problems. Post-defecatory pain and bleeding were checked.

At the end of the 48 months, the healing rate was $90 \%$. In this study no incontinence, infection, recurrence or mortality was seen.

\section{Discussion}

Chronic anal fissure is one of the most common diseases of general surgery. Chronic anal fissure is suspected in the presence of pain and moderate rectal hemorrhage following a typical defecation, and the final diagnosis is reached by clinical examination. For initial therapy, intake of a high-fiber diet and adequate fluid, sitz baths, and topical analgesics are recommended. However, because of the relationship of anal sphincter spasm with anal fissure, the aforementioned therapies generally fail and anal fissures become chronic [6]. Therefore, treatment approaches should be aimed at elimination of anal sphincter spasm. Recently, botulinum toxin, which leads to chemical denervation of the internal sphincter, has been used along with treatments involving topical ointments containing glyceryl trinitrate, diltiazem and nifedipine. The efficiency of botulinum toxin over lateral internal sphincterotomy, which is still recognized as the gold standard in the treatment of chronic anal fissures, has been a focus of recent studies. Despite obtaining successful results with lateral internal sphincterotomy, due to its disadvantages such as invasive nature, requirement of hospital stay and general anesthesia, and risk of fecal incontinence, investigators have focused their studies on treatment with botulinum toxin [7].

Botulinum toxin is a neurotoxin produced by the microorganism Clostridium botulinum. It provides muscle relaxation by blocking neurotransmitter release. Moreover, it shows an analgesic effect via inhibiting neuropeptide release in nociceptors [8]. Clostridium bot- 
ulinum was first shown to have potential for treatment of anal fissures in 1993 and it demonstrated a 73\% success rate in a double-blind randomized study performed in 1998 [9]. The following studies investigated its efficacy over topical nitrate therapy and it was found to be a better option (96\% vs. $60 \%$ ). Recently, the use of botulinum toxin in combination with topical nitrates has been shown to be more successful $[10,11]$.

While medium-term results of treatment with botulinum toxin demonstrated a total recovery in $75 \%$ of cases in 6 months, the recurrence rate in long-term results was $55 \%$ in 3 years and $41.5 \%$ in a 42 -month period $[6,12]$. The occurrence of such varying results in studies on botulinum toxin can be attributed to the differences in patient selection criteria, different application techniques of botulinum toxin, and use of varying dose and injection sites [13]. Similarly, the body weight/dosage ratio may influence the recovery as well. However, this requires further clinical studies. As yet, no consensus of opinion could be reached on the dose, injection site, and number of injections to be used in botulinum toxin treatment [14-16]. However, a 20-25 U dose and anterior injection are recommended due to previous accounts showing better efficacy and less adverse effects. In the present study, patient selection criteria were similar to those in other studies. Patients treated with botulinum toxin presented with fissures having a history of less than 1 year and uncomplicated nature. However, none of our patients had diseases such as diarrhea, irritable bowel syndrome, or diabetes, which are recommended to be checked before LIS by the American Society of Colon and Rectal Surgeons [10, 17]. Botulinum toxin was applied at a standard dose of $25 \mathrm{U}$. Botulinum toxin was injected on both margins of the fissure, at the 9 o'clock position in the lateral aspect. No complication other than pain was observed during the treatment.

Currently, botulinum toxin is preferred over surgery because it shows less adverse effects and requires no anesthesia, as well as being easy to apply and costeffective. As clearly seen in the current study, due to the good results of long-term studies and the outlined advantages, we recommend the use of botulinum toxin treatment on selected patients. Selection of cases having an uncomplicated fissure and a history of symptoms less than 1 year seems to be more appropriate in terms of recurrence in the long term.

\section{References}

1. Lindsey I, Jones OM, Cunningham C, Mortensen NJ. Chronic anal fissure. Br J Surg 2004; 91: 270-9.

2. Collins EE, Lund JN. A review of chronic anal fissure management. Tech Coloproctol 2007; 11: 209-23.
3. Maria G, Brisinda G, Bentivoglio AR, et al. Botulinum toxin injections in the internal anal sphincter for the treatment of chronic anal fissure. Ann Surg 1998; 228: 664-9.

4. Mente BB, İrkörücü O, Akın M, et al. Comparison of botulinum toxin injection and lateral internal sphincterotomy for the treatment of chronic anal fissure. Dis Colon Rectum 2003; 46: 232-7.

5. Essani R, Sarkisyan G, Beart RW, et al. Cost-saving effect of treatment algoritm for chronic anal fissure: a prospective analysis. J Gastrointest Surg 2005; 9: 1237-43.

6. Jost WH. One hundred cases of anal fissure treated with botulin toxin. Dis Colon Rectum 1997; 40: 1029-32.

7. Arroyo A, Perez F, Serrano P, et al. Long-term results of botulinum toxin for the treatment of chronic anal fissure: prospective clinical and manometric study. Int J Colorectal Dis 2005; 20: 267-71.

8. Brisinda G, Maria G, Spanga G, et al. Effectiveness of higher doses of botulinum toxin to induce healing in patients with chronic anal fissures. Surgery 2002; 131: 179-84.

9. Jost WH, Schimrigk K. Use of botulinum toxin in anal fissure. Dis Colon Rectum 1993; 36: 974.

10. Brisinda G, Maria G, Bentivoglio AR, et al. A comparison of injections of botulinum toxin and topical nitroglycerin ointment for the treatment of chronic anal fissure $\mathrm{N}$ Engl J Med 1999; 341: 65-9.

11. Lysy J, Israelit-Yatzkan Y, Sestiery-Ittah M, et al. Topical nitrates potentiate the effect of botulinum toxin in the treatment of patients with refractory anal fissure. Gut 2001; 48: 221-4.

12. Arroyo A, Perez F, Serrano P, et al. Surgical versus chemical (botulinum toxin) sphincterotomy for chronic anal fissure: long term results of a prospective randomized clinical and manometric study. Am J Surg 2005; 189: 429-34.

13. Fruehauf $H$, Fried $M$, Wegmueller $B$, et al. Efficacy and safety of botulinum toxin $\mathrm{A}$ injection compared with topical nitroglycerin ointment for the treatment of chronic anal fissure: a prospective randomized study. Am J Gastroenterol 2006; 101: 2107-12.

14. Sileri P, Mele A, Vito MS, et al. Medical and surgical treatment of chronic anal fissure: a prospective study. J Gastrointest Surg 2007; 11: 1541-8.

15. Baraza W, Boereboom C, Shorthouse A, Brown S. The longterm efficacy of fissurectomy and botulinum toxin injection for chronic anal fissure in females. Dis Colon Rectum 2008; 51 : 239-43.

16. Minguez $M$, Herreros $B$, Espi $A$, et al. Long-term follow up (42 months) of chronic anal fissure after healing with botulinum toxin. Gastroenterology 2002; 123: 112-7.

17. Trzcinski R, Dziki A, Tchorzewski B. Injections of botulinum toxin for the treatment of anal fissures. Eur J Surg 2002; 168: 720-3. 